\title{
Winter Wheat Crop Height Estimation Using Small Unmanned Aerial System (sUAS)
}

\author{
Marife Kung Villareal' ${ }^{1}$, Alejandro Fernandez Tongco², Joe Mari J. Maja ${ }^{3^{*}}$ \\ ${ }^{1}$ University of San Carlos Talamban Campus, Nasipit Talamban Cebu City, Philippines \\ ${ }^{2}$ School of Engineering, University of San Carlos, Cebu City, Philippines \\ ${ }^{3}$ Sensor and Automation Laboratory Edisto Research and Education Center, Clemson University, Blackville, SC, USA \\ Email: mkvillareal27@gmail.com, aftongco@usc.edu.ph, ${ }^{\star}$ jmaja@clemson.edu
}

How to cite this paper: Villareal, M.K., Tongco, A.F. and Maja, J.M.J. (2020) Winter Wheat Crop Height Estimation Using Small Unmanned Aerial System (sUAS). Agricultural Sciences, 11, 355-368. https://doi.org/10.4236/as.2020.114021

Received: March 3, 2020

Accepted: March 29, 2020

Published: April 1, 2020

Copyright (c) 2020 by author(s) and Scientific Research Publishing Inc. This work is licensed under the Creative Commons Attribution International License (CC BY 4.0).

http://creativecommons.org/licenses/by/4.0/

\section{(c) (i) Open Access}

\begin{abstract}
Deploying the small Unmanned Aerial System (sUAS) for data collection of high-resolution images is a big potential in determining crop physiological parameters. The advantage of using sUAS technology is the ability to acquire a high-resolution orthophoto and a 3D Model which is highly suitable for plant height monitoring. Plant height estimation has a big impact in the growth and development of wheat because it is essential for obtaining biomass, which is a factor for higher crop yield. Plant height is an indicator of high yield estimation and it correlates to biomass, nitrogen content, and other plant growth parameters. The study is aimed to determine an accurate height of wheat using the sUAS generated Digital Surface Model (DSM). A high-resolution imagery between $1.0-1.2 \mathrm{~cm} /$ pixel was obtained from a 35 $\mathrm{m}$ altitude with area coverage of 1.01 hectares. The DSM and orthophoto were generated from the sUAS, and the computed wheat heights were derived from the difference of Digital Elevation Model (DEM) and DSM data. Field measurement using steel tape was done for ground truth. The sUAS-based wheat height data were evaluated using the ground truth of 66 wheat-rows by applying correlation and linear regression analysis. Datasets were collected from three different flight campaigns (March 2018-May 2018). The sUAS-based wheat height data were significantly correlated, obtaining the result of $R^{2}=0.988, R^{2}=0.996$ and $R^{2}=0.944$ for the month of March, April and May 2018 respectively. The significance of linear regression results was also validated by computing for the $\mathrm{p}$-value. The $\mathrm{p}$-value results were 0.00064 , 0.0000824 and 0.0058 respectively. The main concern is the lodging of winter wheat, especially during the month of April which affects the recording of the plant's height. Because some of the wheat plants are now lying on the ground, so measurements are done vertically. Nonetheless, the results showed that sUAS technology is highly suitable for many agricultural applications.
\end{abstract}




\section{Keywords}

Small Unmanned Aerial Vehicle, Plant Height, DSM, DEM

\section{Introduction}

Wheat (Triticum aestivum L. em Thell.) is the first important and strategic cereal crop for most of the world's population. It is the most important staple food of about two billion people (36\% of the world population) in different corners of the world. World-wide, wheat provides nearly $55 \%$ of carbohydrates and $20 \%$ of the food calories consumed globally [1]. It exceeds in land and production compared to other grain crop (including rice, maize, etc.) and is, therefore, the most important cereal grain crop of the world. For monitoring of the wheat growth, the height of the wheat is one of the important parameters. The monitoring of the height changes at different times, allows agronomists and breeders to determine the health and growth of wheat. Plant height information and spatial distribution are valuable in the classification of crop features for precision agriculture [2]-[7]. It is an important parameter that can provide indications on the growth rate and health of plants, high crop yield estimation, proper crop monitoring, and ecological research in regional and global scales [8]-[13]. Moreover, plant height is an important factor for crop management and harvesting processes like crop yield predictions, precise fertilizer application, pesticide application and a key variable in determining yield potential [14] [15] [16] and in modeling yield losses from lodging [17] [18].

Remote sensing technology such as the sUAS is a technological advancement in imagery acquisition for monitoring plants. Extensive agricultural studies have used multi-rotor and fixed wing sUAS platforms to carry various types of miniaturized sensors to effectively perform crop monitoring tasks under a variety of circumstances [19] [20] [21]. It has been demonstrated that sUAS platforms offer a unique opportunity to develop a variety of precision agriculture applications with a focus on assessing crop growth, vegetation and health status [22] [23] [24] [25]. Data collection with sUAS fills a gap on the observational scale in remote sensing by delivering high spatial and temporal resolution data that is required in crop growth monitoring. Biophysical parameters such as plant height and biomass are monitored to describe crop growth and serve as an indicator for the final crop yield [26].

The UAS can obtain high-resolution images with higher temporal, spatial and ground resolution with as compared to satellite images. Small-sized remote sensing sensors can be mounted on sUAS, which makes sUAS platforms increasingly popular in agricultural applications [27] [28]. The use of sUAS in agricultural and environmental applications has numerous advantages compared with conventional aerial vehicles, including lower cost, weight, and flight speed and 
flight altitude [28]. With very high-resolution imagery DSMs generated from sUAS photogrammetry have become common in several research areas, including landslide analysis in geology [29].

Plant height relies on the development of very high-resolution digital models to be able to identify and retrieve the height of each plant. High-resolution imagery is a standard methodology used for the generation of DSM [30]. DSM data have been used for estimating crop height and other growth parameters [6]. DSM depends on the quality of the UAV images and the ease of detecting such points, which could be improved by optimizing the values of image contrast, saturation and brightness [31]. Previous studies show the applicability of a very high-resolution DSM and orthoimage mosaics with high spatial and temporal resolution [28] [31] [32] [33] for environmental monitoring [34], and tree crown height quantification [30].

Although, there were a lot of researches about height estimation using DSM the method or process of calculating the height of a crop is not straightforward and entails manipulation of data to derive an accurate height of the plants.

The objective of this study is to determine the height of wheat with the sUAS generated DSM and DEM. This paper demonstrates the methods to test the accuracy of deter-mining wheat height using a sUAS with the validation of field height measurement.

\section{Materials and Method}

\subsection{Study Area}

In this study, the data collection was carried out during the months of March 14, April 11, and May 9 of 2018 at the University of Florida, particularly the University of Florida's Institute of Food and Agricultural Sciences (UF/IFAS), Quincy, Florida ( $\left.30^{\circ} 32^{\prime} 46.3^{\prime \prime} \mathrm{N}, 84^{\circ} 35^{\prime} 40.0^{\prime \prime} \mathrm{W}\right)$ as shown in Figure 1.

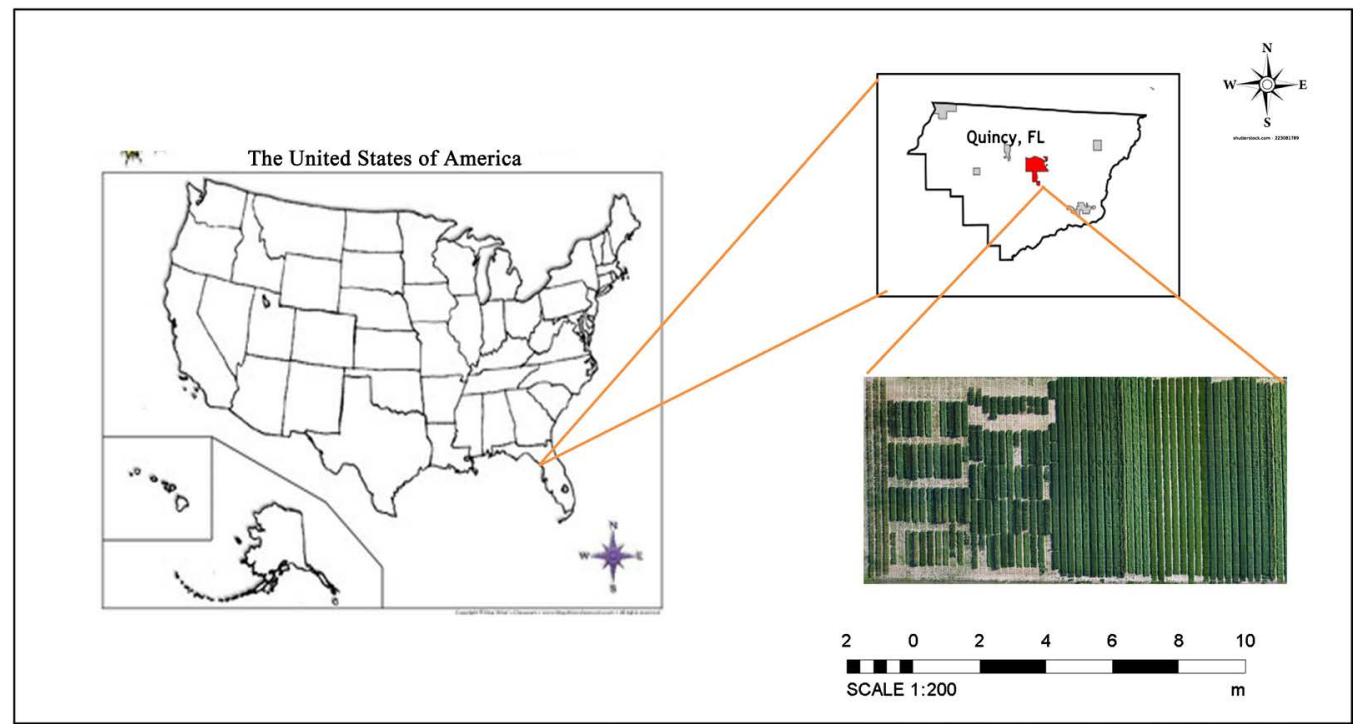

Figure 1. Study Area in UF-IAFS, Quincy Florida. 
The wheat crop area is 1.01 hectare as shown in Figure 2. The varieties of wheat planted were Grazer Pro Wheat, Grazer Max Wheat, and Maxie Wheat. Grazer Pro Wheat has an approximate observed height of 11 inches, Grazer Max Wheat has an approximate observed height of 13 inches, while Maxie Wheat has an approximate observed height of 12 inches. These varieties of wheat are planted in autumn to germinate and develop into young plants that remain in the vegetative phase during the winter and resume growth in early spring. These three varieties usually are planted from September to November and harvested in the summer or early autumn of the following year.

The sUAS imagery and field measurements were taken on three separate times: March 14, 2018 (Boot stage), April 11, 2018 (Flowering Stage) and May 9, 2018 (Ripening Stage) as shown in Figure 2. The weather for the flying flight date is shown in Table 1.

\subsection{Unmanned Aerial System}

The sUAS used in this study is an Inspire 2 (Da Jiang Innovations, Shenzhen, China). The sUAS is a multi-rotor type with four retractable propellers, and the frame consists of a magnesium aluminum composite shell with a carbon fiber

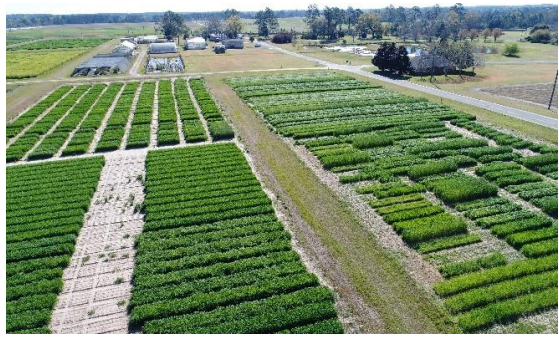

March 14, 2018 (in Boot)

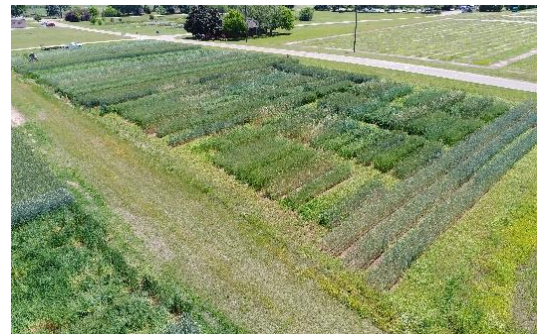

April 11, 2018 (Flowering)

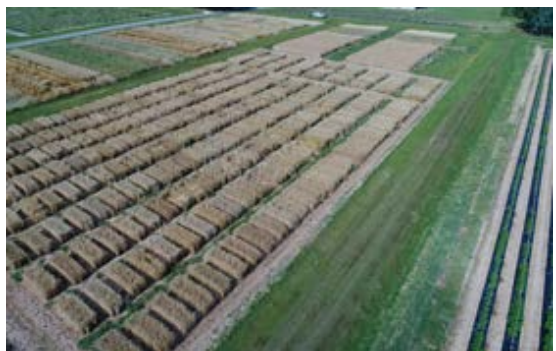

May 10, 2018 (Ripening)

Figure 2. Images were captured by the DJIX4S camera attached to the sUAS.

Table 1. Weather data on each flight date.

\begin{tabular}{cccc}
\hline \multirow{2}{*}{ Date } & \multicolumn{2}{c}{ Temperature (F) } & Precip. \\
\cline { 2 - 4 } & High & Low & \\
\hline March 14, 2018 & 60.1 & 34.0 & 0.0 \\
April 11, 2018 & 66.9 & 46.0 & 0.0 \\
May 09, 2018 & 89.1 & 57.9 & 0.0 \\
\hline
\end{tabular}


arm as shown in Figure 3. It has a dual self-heating battery to provide redundancy. This type of sUAS is specifically designed for filmmaking. The camera used for normal imagery is the X4S (Da Jiang Innovations, Shenzhen, China) Camera from the same manufacturer.

Aside from the X4S camera, there were three different multispectral sensors attached to the sUAS during the flight campaign, modified Canon Camera Elph130IS (Canon, One Canon Park, NY, USA), MAPIR Survey2 (Peau Productions, San Diego, CA, USA), and Parrot Sequoia (Micasense Inc., Seattle, WA, USA). A carbon-fiber mount was created for these three different multispectral sensors to hold all the sensors, including the battery, for the Parrot Sequoia as shown in Figure 4. The multispectral data were used for other purposes not related to this project.

\subsection{Field Measurement for Validation}

There were sixty-six plant rows of wheat which are of different heights. There were rows that have the same height which made the plants' measurement easier. Measurements were taken for each height of wheat found in the area. Crop height was measured using a steel tape as shown in Figure 5.

\subsection{Image Acquisition and Processing}

A set of images of the plot was acquired on March 15, 2018, April 11, 2018 and May 11, 2018. During each flight, the sUAS route was created through DJI GS Pro with 10 waypoints. The altitude that was used for each of the flights was 35 $\mathrm{m}$. This was due to the size of the plot and the battery capacity of the sUAS and

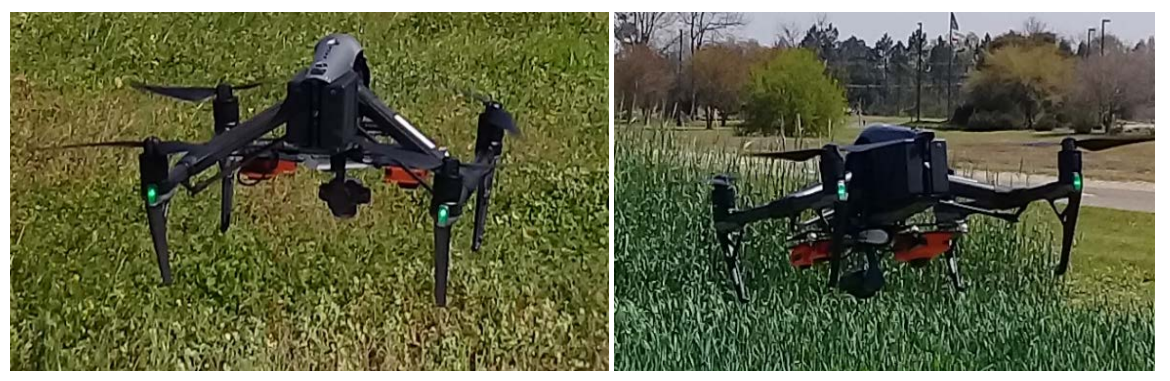

Figure 3. sUAS used in this study.

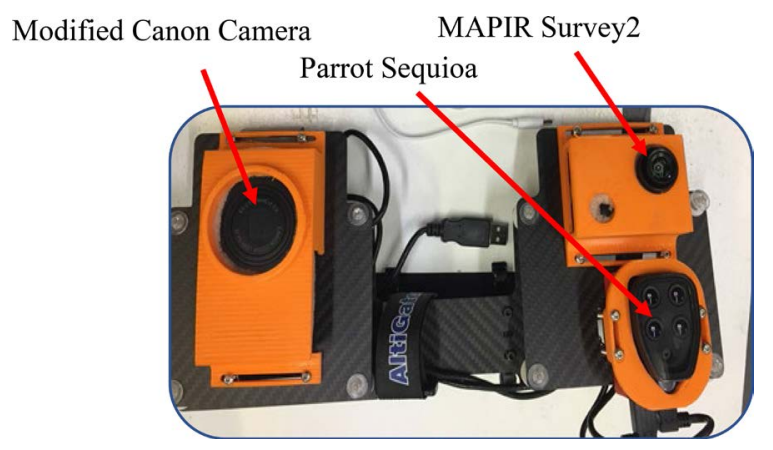

Figure 4. Multispectral Sensor. 

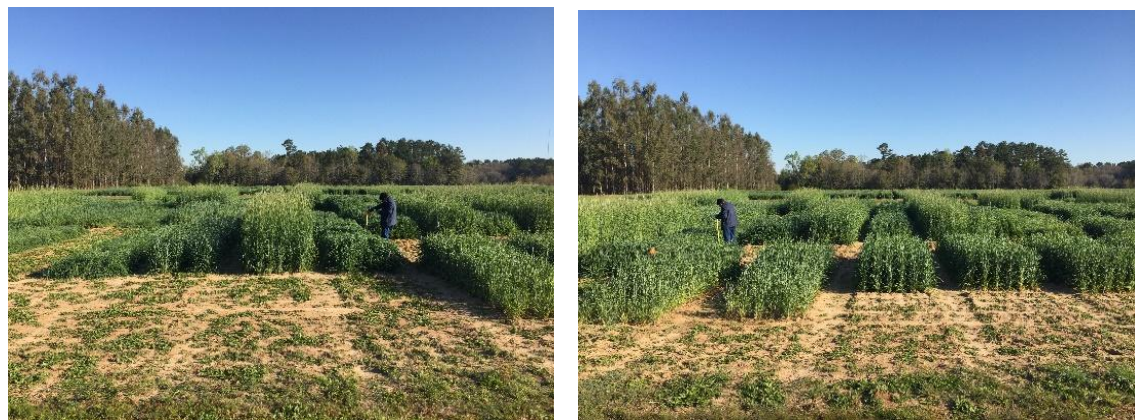

Figure 5. Field measurement was taken using a steel tape per plant row of wheat.

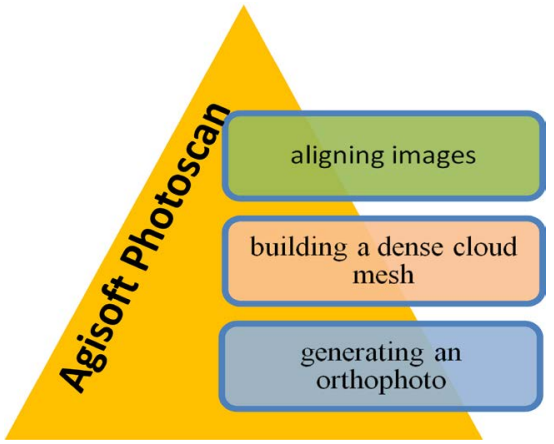

Figure 6. Workflow Process.

load (sensors). A forward and side overlap of $80 \%$ and $70 \%$ respectively were used for the same flight.

The set of sUAS aerial images was processed to create an orthophoto image of each of multispectral sensors using Agisoft Photoscan Professional Software (Agisoft LLC, St. Petersburg, Russia). This automatic workflow process involved aligning images, building a dense cloud, mesh, and generating an orthophoto and DSM as shown in Figure 6. The resulting images (orthophoto and DSM) are shown in Figure 7. These images have been calibrated using the different calibration panel provided by the manufacturer reflected in Figure 8. Shown in Table 2 are the acquisition details of points and images.

\subsection{Statistic Analysis}

The method used for the analysis of the data obtained from sUAS data and field data of wheat height is linear regression. The relationships between the two data gathered were shown in Figures 10-12.

\section{Results and Discussion}

\section{1. sUAS-Based Height Estimation}

The sUAS-based RGB imaging was able to obtain two types of models, the DEM, which is the ground elevation, and the DSM, which is the surface vegetation. The DEM and DTM represent the spatial distribution of terrain attributes [35]. DEMs are a type of raster GIS layer. In a DEM, each cell of the raster GIS layer 
has a value corresponding to its elevation (z-values at regularly spaced intervals). DEM data files contain the elevation of the terrain over a specified area, usually at a fixed grid interval over the Bare Earth. A DTM can be described as a three-dimensional representation of a terrain surface consisting of $\mathrm{X}, \mathrm{Y}, \mathrm{Z}$ coordinates stored in digital form. It includes not only heights and elevations, but other geographic elements and natural features such as rivers, ridge lines, etc. A DTM is
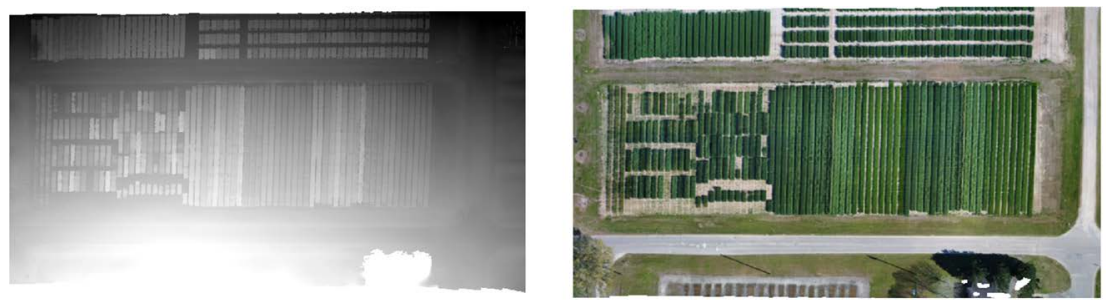

(a)
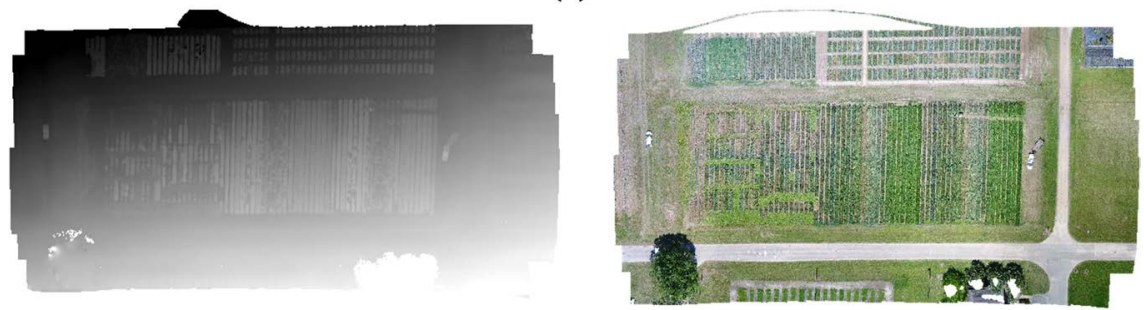

(b)
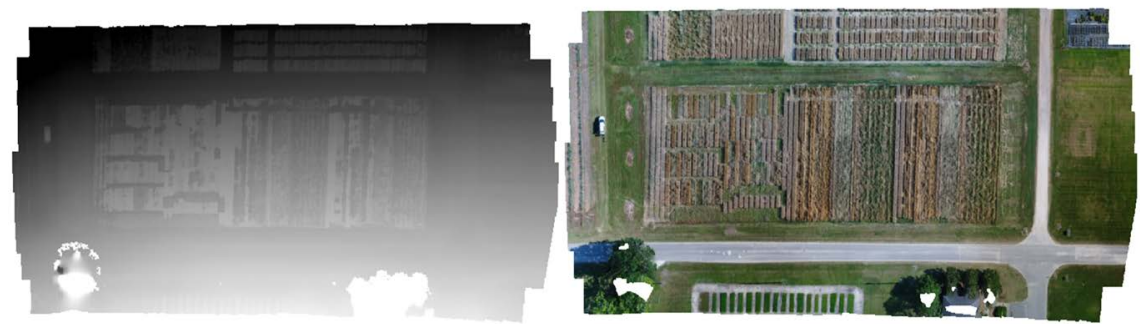

(c)

Figure 7. DSM and Orthophoto from flight of (a) March 15, 2018, (b) April 11, 2018, and (c) May 10, 2018.

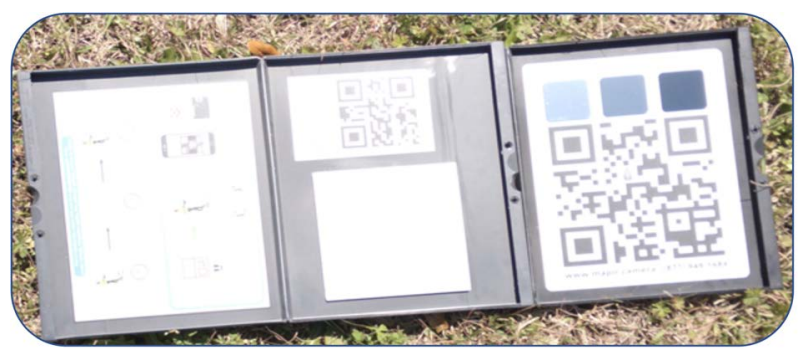

Figure 8. Calibration panel for the Multispectral sensors.

Table 2. Acquisition details of points and images.

\begin{tabular}{ccccccc}
\hline Altitude & Waypoints & $\begin{array}{c}\text { Flight } \\
\text { Length }\end{array}$ & $\begin{array}{c}\text { Main } \\
\text { Path No. }\end{array}$ & $\begin{array}{c}\text { Flight Time } \\
\text { Est. }\end{array}$ & $\begin{array}{c}\text { No. of } \\
\text { Images }\end{array}$ & $\begin{array}{c}\text { Capture } \\
\text { Interval }\end{array}$ \\
\hline $35 \mathrm{~m}$ & 10 & $867 \mathrm{M}$ & 5 lines & $4 \mathrm{~m} 57 \mathrm{~s}$ & 113 & F:7.0 M/S: $10.9 \mathrm{M}$ \\
\hline
\end{tabular}


a DEM that has been augmented by elements such as break lines and observations other than the original data to correct for artifacts produced by using only the original data. The DSM represents the MSL elevations of the reflective surfaces of trees, buildings, and other features elevated above the Bare Earth. These models are important to determine plant height. Plant height can be obtained by subtracting DEM from DSM [36] [37] as shown in Equation (1). The constant $(k)$ was used to address a small error which most likely caused the software used during stitching. Stitch images are prone to anomalies when the two images are combined and create a blurred area on where the two images are stitched. The calculated $k$ was based on $30 \%$ of the dataset.

$$
\mathrm{PH}=\left(H_{D S M}-H_{D E M}\right)+k
$$

\subsection{Height Accuracy}

Data gathering and monitoring were taken in three months as shown in Figure 9. The first field measurements were taken on March 15, 2018 when wheat height varied from 1 foot to 4 feet. The second data was taken on April 11, 2018 when the plants' height was from 1.6 to 5 feet. The third data was taken on May 9, 2018 with the plants' height ranging from 3 to 4.9 feet. Lodging occurred to some of the crops due to strong wind and heavy rain, thus the height of the wheat was affected as shown in Figure 9(c). An average of the height was taken from the area where lodging occurred. Thirty percent (30\%) of the area was used as the calibration of height measurement. While the rest of the plot was used to calculate the height based on the calibrated equation. The constant $k$ used for this data collection was -0.89 .

The sUAS-based height data were validated by the measured height data using the steel tape. There are sixty-six rows of wheat with different heights. The results of the measured wheat height vs. the sUAS-based wheat height was able to obtain a result of $R^{2}=0.988$ (March 15, 2018), $R^{2}=0.996$ (April 11, 2018), and $R^{2}=0.944$ (May 2018). Shown in Figures 10-12 were the results of the correlation and regression analysis for the three months, respectively. The results were shown in scattered plots and evaluated based on their coefficient of determination $\left(R^{2}\right)$ and $\mathrm{p}$-value. The $\mathrm{p}$-value for the sUAS-based wheat height data and ground truth data are $0.00064,0.0000824$, and 0.0058 for March, April and May, respectively. The p-value results indicate that sUAS-based wheat height is significantly correlated with the ground truth data.

\section{Conclusions}

This study is to determine the height of wheat with the sUAS generated DSM and DEM, specifically to demonstrate the methods to test the accuracy of determining wheat height using a sUAS with the validation of field height measurement. Three field measurements were taken in the course of the study (March-May 2018). Due to unforeseen circumstances (weather, e.g. heavy rain and 


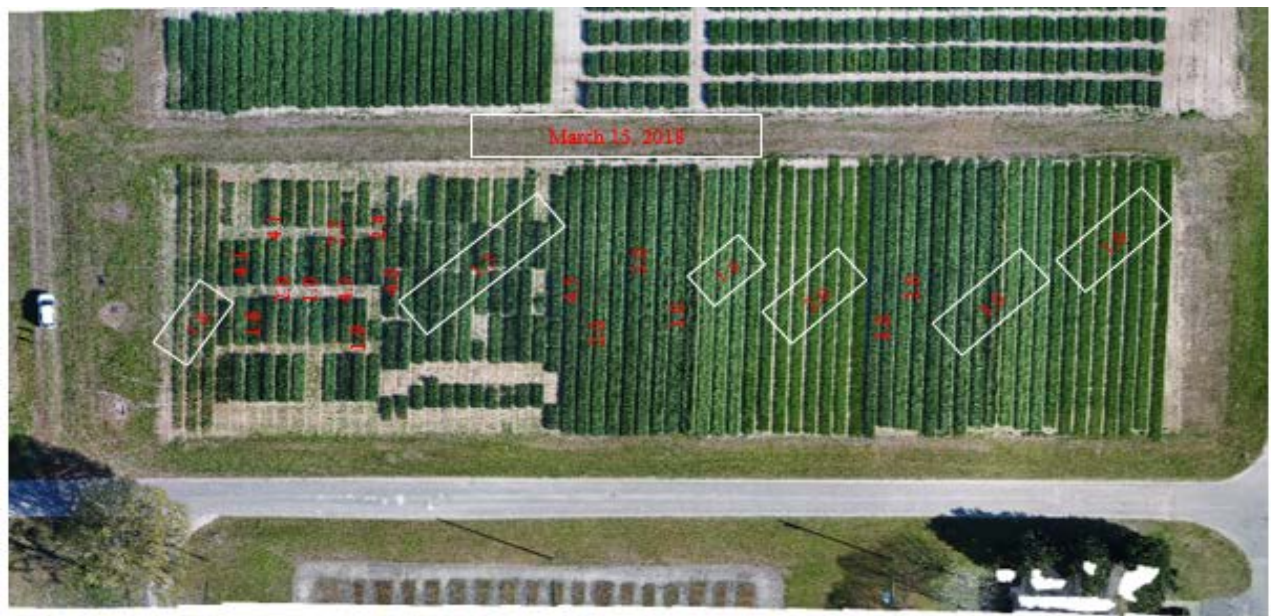

(a)

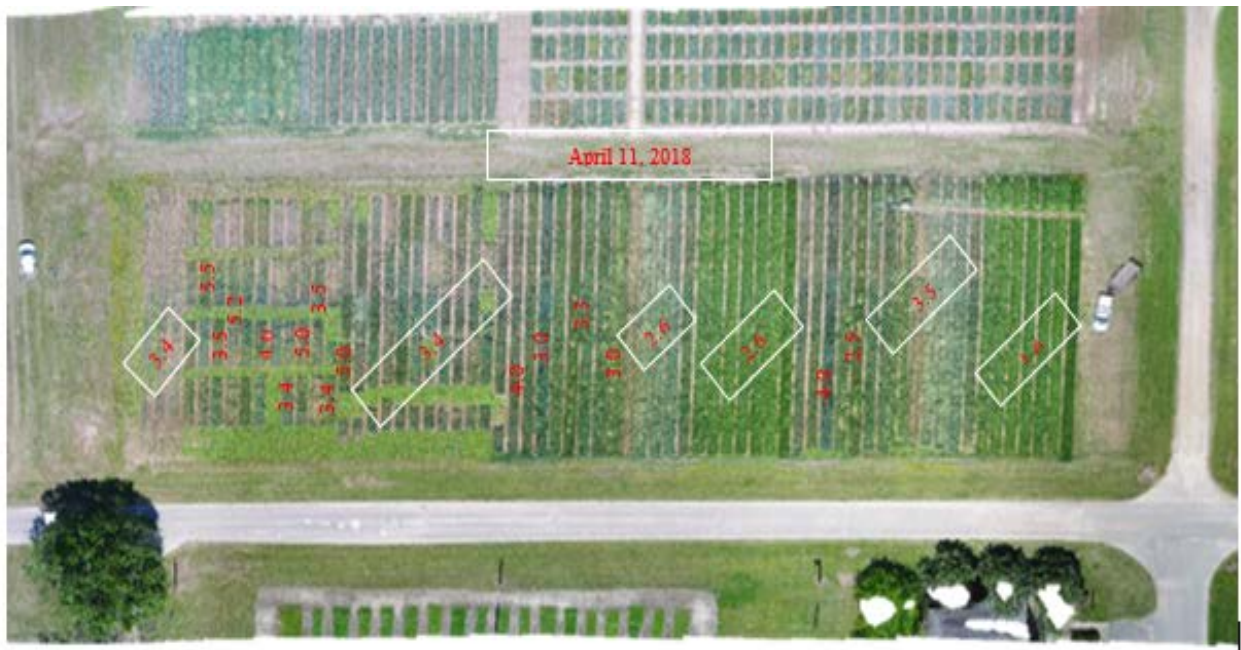

(b)

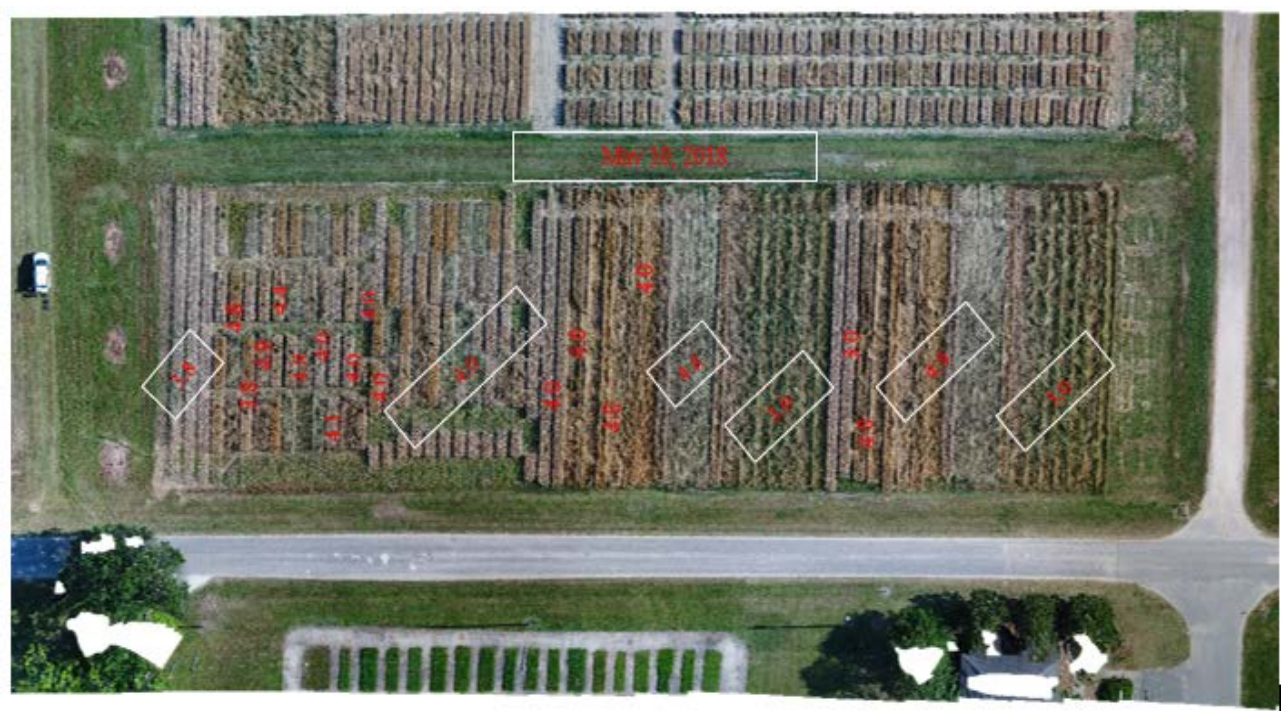

(c)

Figure 9. Height of wheat taken by field survey from (a) March, (b) April, and (c) May 2018. 


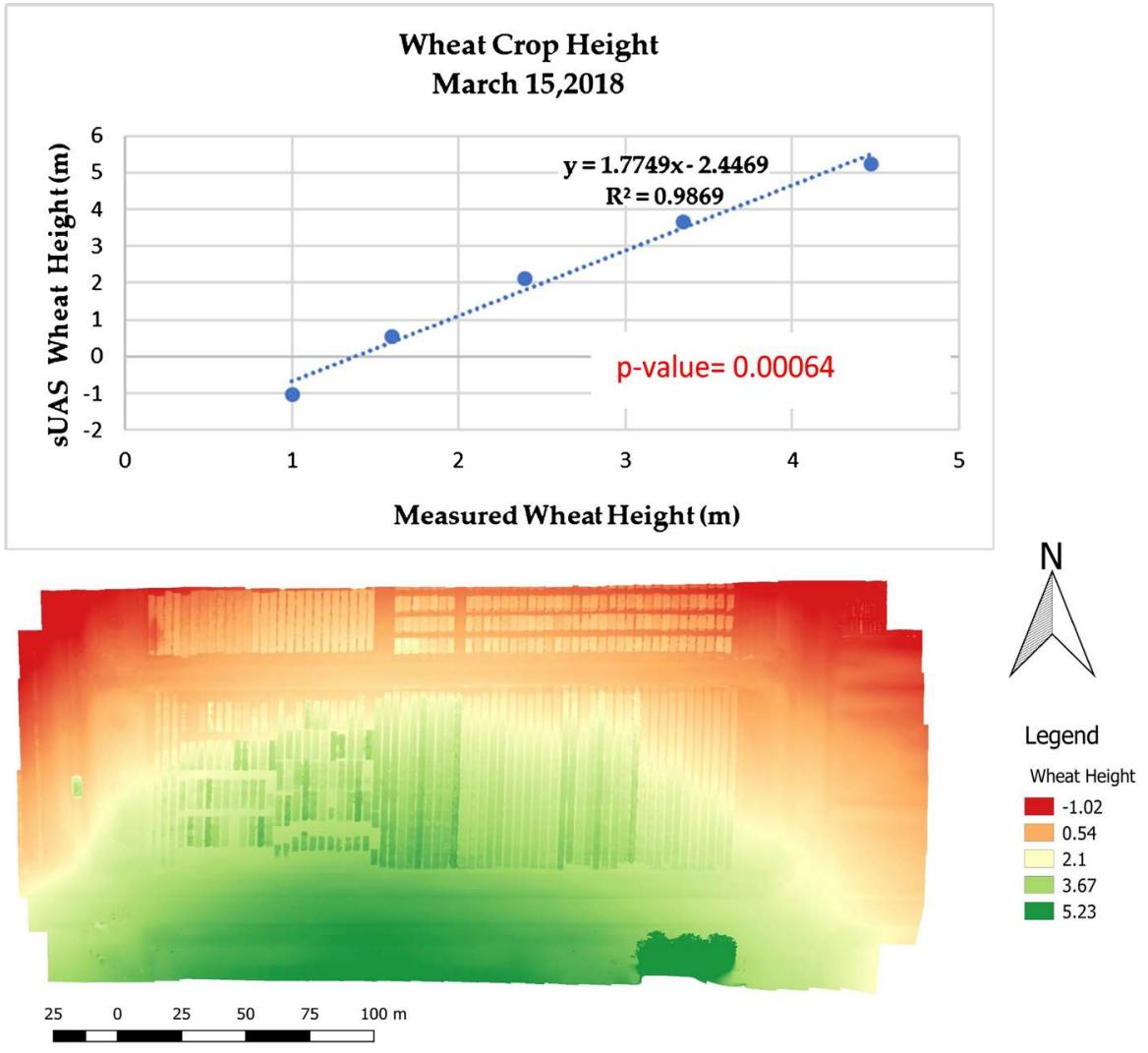

Figure 10. Measured wheat height vs. sUAS wheat height in meters, taken March 15, 2018.

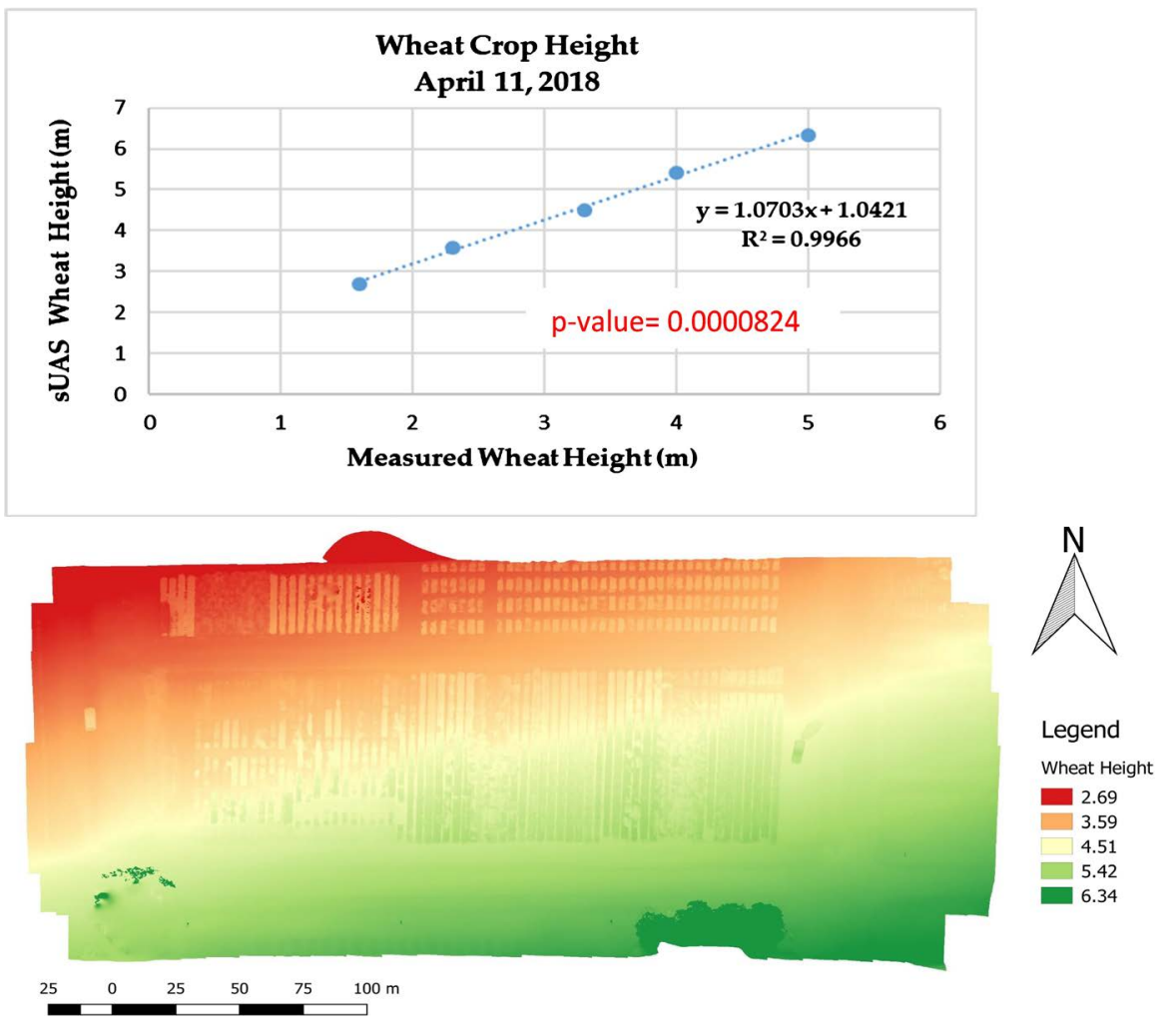

Figure 11. Measured wheat height vs. sUAS wheat height in meters, taken April 11, 2018. 


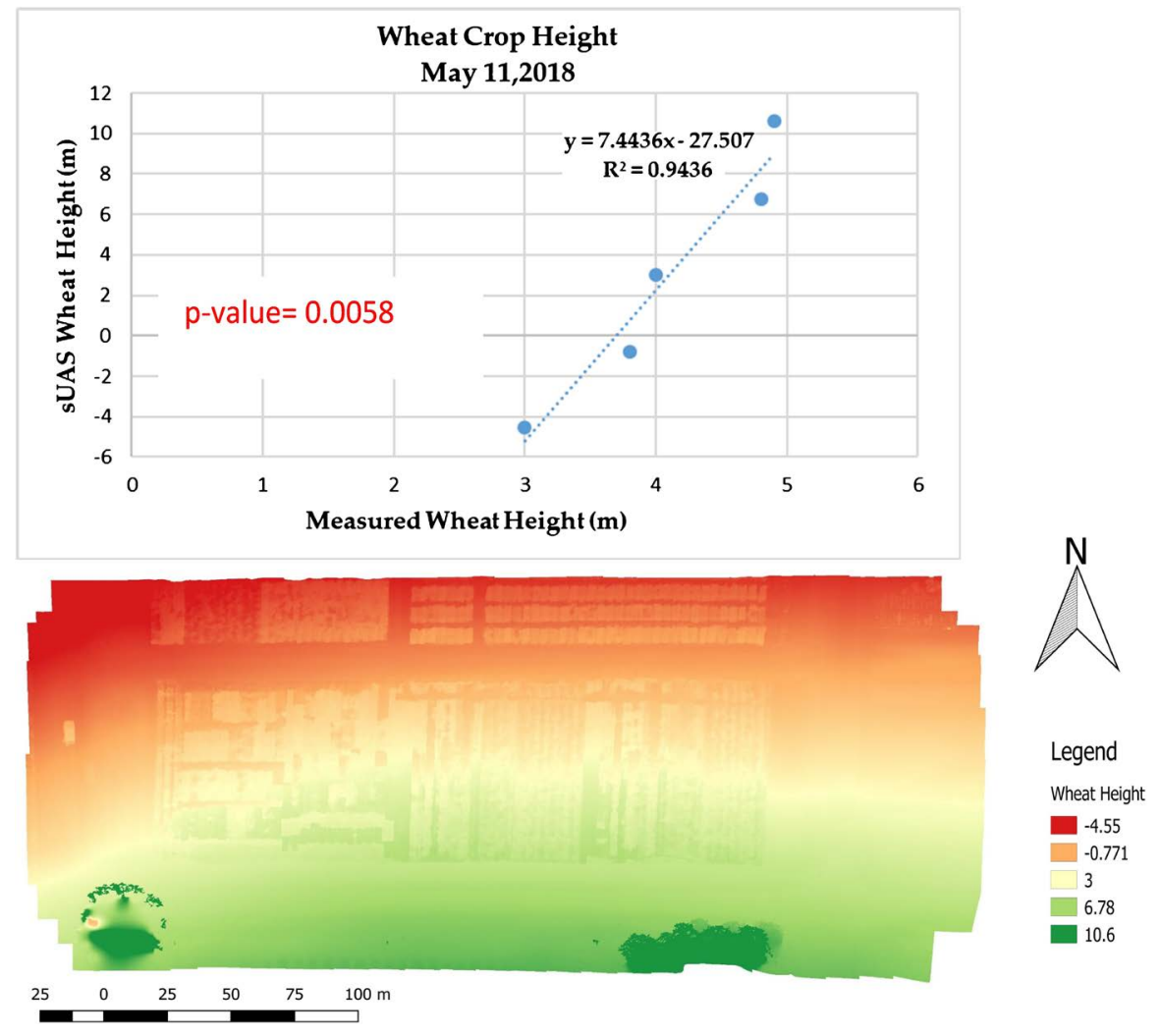

Figure 12. Measured wheat height vs. sUAS wheat height in meters, taken May 11, 2018.

strong winds) in May 2018, lodging occurred to some of the areas where the study was conducted. Results showed that the calculated height from sUAS from the measured height was highly correlated $\left(R^{2}=0.988, R^{2}=0.996\right.$, and $R^{2}=$ $0.944)$ for the three months. The p-value results indicate that sUAS-based wheat height is significantly correlated with the ground truth data. The results showed that sUAS imagery is an effective alternative method to determine the plant height of winter wheat.

Though problems with nature, such as heavy rains and strong winds were encountered, which affects plant height measurements because of the lodging of wheat; the results still show relatively high accuracy. Future work will focus on the determination of the root cause of the small error calculation. Another source for this error might be on the camera itself.

\section{Acknowledgements}

This work was partially supported by a grant from Silliman University and is based on work supported by NIFA/USDA under project numbers SC-1700540 and SC-1700543. The authors would like to acknowledge the help of Mr. Bolton, and Dr. Wiggins Zaddarreyal of the University of Florida, for allowing us to use the winter wheat plot at the University of Florida's Institute of Food and Agricultural Sciences Research and Education Center in Quincy, Florida as our study site. 


\section{Conflicts of Interest}

The authors declare no conflicts of interest regarding the publication of this paper.

\section{References}

[1] Breiman, A. and Graur, D. (2013) Wheat Evolution. Israel Journal of Plant Sciences, 43, 85-98. https://doi.org/10.1080/07929978.1995.10676595

[2] Lee, D.S. and Shan, J. (2003) Combining Lidar Elevation Data and Ikonos Multispectral Imagery for Coastal Classification Mapping. Marine Geodesy, 26, 117-127. https://doi.org/10.1080/01490410306707

[3] Bork, E. and Su, J. (2007) Integrating LIDAR Data and Multispectral Imagery for Enhanced Classification of Rangeland Vegetation: A Meta-Analysis. Remote Sensing of Environment, 111, 11-24. https://doi.org/10.1016/j.rse.2007.03.011

[4] Geerling, G., Labrador-Garcia, M., Clevers, J.G.P., Ragas, A.M. and Smits, A.J. (2007) Classification of Floodplain Vegetation by Data Fusion of Spectral (CASI) and Lidar Data. International Journal of Remote Sensing, 28, 4263-4284. https://doi.org/10.1080/01431160701241720

[5] Kempeneers, P., Deronde, B., Provoost, S. and Houthuys, R. (2009) Synergy of Airborne Digital Camera and Lidar Data to Map Coastal Dune Vegetation. Journal of Coastal Research, 53, 73-82. https://doi.org/10.2112/SI53-009.1

[6] De Souza, C.H.W., Lamparelli, R.A.C., Rochaa, J.V. and Magalhães, P.S.G. (2017) Height Estimation of Sugarcane Using an Unmanned Aerial System (UAS) Based on Structure from Motion (SfM) Point Clouds. International Journal of Remote Sensing, 38, 2218-2230. https://doi.org/10.1080/01431161.2017.1285082

[7] Bendig, J., Yu, K., Aasen, H., Bolten, A., Bennertz, S., Broscheit, J., Gnyp, M.L. and Bareth, G. (2015) Combining UAV-Based Plant Height from Crop Surface Models, Visible, and near Infrared Vegetation Indices for Biomass Monitoring in Barley. International Journal of Applied Earth Observation \& Geoinformation, 39, 79-87. https://doi.org/10.1016/j.jag.2015.02.012

[8] Li, W., et al. (2016) Remote Estimation of Canopy Height and Aboveground Biomass of Maize Using High-Resolution Stereo Images from a Low-Cost Unmanned Aerial Vehicle System. Ecological Indicators, 67, 637-648. https://doi.org/10.1016/j.ecolind.2016.03.036

[9] Houghton, A., Hall, F. and Goetz, J. (2009) Importance of Biomass in the Global Carbon Cycle. Journal of Geophysical Research: Biogeosciences, 114, 1-13. https://doi.org/10.1029/2009JG000935

[10] Badhwar, D. and Macdonald, B. (1986) Satellite-Derived Leaf-Area-Index and Vegetation Maps as Input to Global Carbon Cycle Models-A Hierarchical Approach. International Journal of Remote Sensing, 7, 265-281. https://doi.org/10.1080/01431168608954680

[11] Liu, R., Chen, M., Liu, J., Deng, F. and Sun, R. (2007) Application of a New Leaf Area Index Algorithm to China's Landmass Using MODIS Data for Carbon Cycle Research. Journal of Environmental Management, 85, 649-658. https://doi.org/10.1016/j.jenvman.2006.04.023

[12] Anthony, D., Elbaum, S., Lorenz, A. and Detweiler, C. (2014) On Crop Height Estimation with UAVs. IROS 2014 Conference Digest, IEEE/RSJ International Conference on Intelligent Robots and Systems, Chicago, 14-18 September 2014, 4805-4812. 
https://doi.org/10.1109/IROS.2014.6943245

[13] Selkowitz, D.J., Green, G., Peterson, B. and Wylie, B. (2012) A Multi-Sensor Lidar, Multi-Spectral and Multi-Angular Approach for Mapping Canopy Height in Boreal Forest Regions. Remote Sensing of Environment, 121, 458-471. https://doi.org/10.1016/j.rse.2012.02.020

[14] Ehlert, D., Adamek, R. and Horn, H.-J. (2009) Laser Rangefinder-Based Measuring of Crop Biomass under Field Conditions. Precision Agriculture, 10, 395-408. https://doi.org/10.1007/s11119-009-9114-4

[15] Lati, R.N., Filin, S. and Eizenberg, H. (2013) Estimating Plant Growth Parameters Using an Energy Minimization-Based Stereovision Model. Computers and Electronics in Agriculture, 98, 260-271. https://doi.org/10.1016/j.compag.2013.07.012

[16] Martin, K.L., Anderson, R.H., Arnall, D.B., Brixcy, K.D., Casillas, M.A., Chung, B., Dobey, B.C., Kamenidou, S.K., Kariuki, S.K., Katsalirou, E.E., Morris, J.C., Moss, J.Q., Rohla, C.T., Sudbury, B.J., Tubana, B.S. and Raun, W.R. (2005) Mid-Season Prediction of Wheat-Grain Yield Potential Using Plant, Soil, and Sensor Measurements. Journal of Plant Nutrition, 29, 873-897. https://doi.org/10.1080/01904160600649187

[17] Berry, P.M., Sterling, M., Baker, C.J., Spink, J. and Sparkes, D.L. (2003) A Calibrated Model of Wheat Lodging Compared with Field Measurements. Agricultural and Forest Meteorology, 119, 167-180. https://doi.org/10.1016/S0168-1923(03)00139-4

[18] Chapman, S., Merz, T., Chan, A., Jackway, P., Hrabar, S., Dreccer, M., Holland, E., Zheng, B., Ling, T. and Jimenez-Berni, J. (2014) Pheno-Copter: A Low-Altitude, Autonomous Remote-Sensing Robotic Helicopter for High-Throughput Field-Based Phenotyping. Agronomy, 4, 279-301. https://doi.org/10.3390/agronomy4020279

[19] Gevaert, C.M., Suomalainen, J., Tang, J. and Kooistra, L. (2015) Generation of Spectral-Temporal Response Surfaces by Combining Multispectral Satellite and Hyperspectral UAV Imagery for Precision Agriculture Applications. IEEE Journal of Selected Topics in Applied Earth Observations and Remote Sensing, 8, 3140-3146. https://doi.org/10.1109/JSTARS.2015.2406339

[20] Rasmussen, J., Nielsen, J., Garcia-Ruiz, F., Christensen, S. and Streibig, C. (2013) Potential Uses of Small Unmanned Aircraft Systems (UAS) in Weed Research. Weed Research, 53, 242-248. https://doi.org/10.1111/wre.12026

[21] Zhang, C. and Kovacs, J.M. (2012) The Applications of Small Unmanned Aerial Systems for Precision Agriculture: A Review. Precision Agriculture, 13, 693-712. https://doi.org/10.1007/s11119-012-9274-5

[22] Lopez-Granados, F., Torres-Sanchez, J., Serr no-Perez, A., de Castro, A., Mesas-Carrascosa, F. and Pena, J. (2016) Early Season Weed Mapping in Sunflower Using UAV Technology: Variability of Herbicide Treatment Maps against Weed Thresholds. Precision Agriculture, 17, 183-199. https://doi.org/10.1007/s11119-015-9415-8

[23] Honkavaara, E., Saari, H., Kaivosoja, J., Polonen, I., Hakala, T. and Litkey, P. (2013) Processing and Assessment of Spectrometric, Stereoscopic Imagery Collected Using a Lightweight UAV Spectral Camera for Precision Agriculture. Remote Sensing, 5, 5006-5039. https://doi.org/10.3390/rs5105006

[24] Li, X., Lee, W.S., Li, M., Ehsani, R., Mishra, A.R. and Yang, C. (2012) Spectral Difference Analysis and Airborne Imaging Classification for Citrus Greening Infected Trees. Computers and Electronics in Agriculture, 83, 32-46. https://doi.org/10.1016/j.compag.2012.01.010

[25] Berni, J.A.J., Zarco-Tejada, P.J., Suarez, L. and Fereres, E. (2009) Thermal and Nar- 
rowband Multispectral Remote Sensing for Vegetation Monitoring from an Unmanned Aerial Vehicle. IEEE Transactions on Geoscience and Remote Sensing, 47, 722-738. https://doi.org/10.1109/TGRS.2008.2010457

[26] Bendig, J.V. (2015) Unmanned Aerial Vehicles (UAVs) for Multi-Temporal Crop Surface Modelling. A New Method for Plant Height and Biomass Estimation Based on RGB-Imaging. PhD Thesis, Universität zu Köln.

[27] Li, W., Niu, Z., Chen, H., Li, D., Wu, M. and Zhao, W. (2016) Remote Estimation of Canopy Height and above Ground Biomass of Maize Using High-Resolution Stereo Images from a Low-Cost Unmanned Aerial Vehicle System. Ecological Indicators, 67, 637-648. https://doi.org/10.1016/j.ecolind.2016.03.036

[28] Sankaran, S., Khot, R., Espinoza, Z., Jarolmasjed, S., Sathuvalli, R., Vandemark, J., Miklas, N., Carter, H., Pumphrey, O. and Knowles, R. (2015) Low-Altitude, High-Resolution Aerial Imaging Systems for Row and Field Crop Phenotyping: A Review. European Journal of Agronomy, 70, 112-123.

https://doi.org/10.1016/j.eja.2015.07.004

[29] Turner, D., Lucieer, A. and Watson, C. (2012) An Automated Technique for Generating Georectified Mosaics from Ultra-High Resolution Unmanned Aerial Vehicle (UAV) Imagery, Based on Structure from Motion (SfM) Point Clouds. Remote Sensing, 4, 1392-1410. https://doi.org/10.3390/rs4051392

[30] Zarco-Tejada, P.J., Diaz-Varelaa, R., Angileria, V. and Loudjania, P. (2014) Tree Height Quantification Using Very High-Resolution Imagery Acquired from an Unmanned Aerial Vehicle (UAV) and Automatic 3D Photo-Reconstruction Methods. European Journal of Agronomy, 55, 89-99. https://doi.org/10.1016/j.eja.2014.01.004

[31] Abdul Salam, R., Osman, A. and Zawawi Talib, A. (2007) Underwater Image Enhancement Using an Integrated Colour Model. IAENG International Journal of Computer Science, 34, 2.

[32] Passoni, D., Pinto, L. and Sona, G. (2014) Use of Unmanned Aerial Systems for Multispectral Survey and Tree Classification: A Test in a Park Area of Northern Italy. European Journal of Remote Sensing, 47, 251-269. https://doi.org/10.5721/EuJRS20144716

[33] Pinto, L., Pagliari, D., Passoni, D. and Gini, R. (2014) Experimental Analysis of Different Software Packages for Orientation and Digital Surface Modelling from UAV Images. Earth Science Informatics, 7, 97-107. https://doi.org/10.1007/s12145-013-0142-2

[34] Fritz, A., Kattenborn, T. and Koch, B. (2013) UAV-Based Photogrammetric Point Clouds-Tree Stem Mapping in Open Stands in Comparison to Terrestrial Laser Scanner Point Clouds. International Archives of the Photogrammetry, Remote Sensing and Spatial Information Sciences, Volume XL-1/W2, Rostock, 4-6 September 2013, 141-146. https://doi.org/10.5194/isprsarchives-XL-1-W2-141-2013

[35] Peckham, R.J. and Jordan, G. (2007) Digital Terrain Modelling: Development and Applications in a Policy Support Environment. Springer, Berlin. https://doi.org/10.1007/978-3-540-36731-4

[36] Demir, N., Sönmez, N.K., Akar, T. and Üna, S. (2018) Automated Measurement of Plant Height of Wheat Genotypes Using a DSM Derived from UAV Imagery. 2nd International Electronic Conference on Remote Sensing, Vol. 2, 350. https://doi.org/10.3390/ecrs-2-05163

[37] GIS Geography (2018) DEM, DSM \& DTM Differences-A Look at Elevation Models in GIS. https://gisgeography.com/dem-dsm-dtm-differences 